\title{
Conceptual design pattern for ergonomic workplaces
}

\author{
Fonseca, Bernardo Bastos ${ }^{\mathrm{a},{ }^{*}}$, Aguilera, Maria Victoria Cabrera ${ }^{\mathrm{b}}$ and Vidal, Mario Cesar Rodríguez ${ }^{\mathrm{c}}$ \\ ${ }^{a}$ Department of Production Engineer, Universidade Federal do Rio de Janeiro, Rio de Janeiro, Brasil, \\ bernardobf@pep.ufrj.br.Bolsista CNPQ \\ ${ }^{\mathrm{b}}$ Department of Production Engineer, Universidade Federal do Rio de Janeiro, Rio de Janeiro, Brasil, \\ victoria@ergonomia.ufrj.br.BolsistaCAPES \\ ${ }^{\mathrm{c}}$ Department of Production Engineer, Universidade Federal do Rio de Janeiro, Rio de Janeiro, Brasil, \\ mvidal@ergonomia.ufrj.br
}

\begin{abstract}
In this paper, we analyzed two laboratories of liquid chromatography (LC), separation technique of mixtures and identification of its components, in order to identify projectual gaps relating to the environment and the working station. The methodology used was the ergonomic analysis with interactional and participatory techniques applied during the activity performance. This work incorporated and adapted the concept developed by Alexander (1979) - pattern languages - passing from architectural projects to workstations project and physical arrangement of the work environment. The adaptation of the concept resulted in a list of recommendations, requirements and concepts that have brought design solutions for the problematic aspects observed in the ergonomic analysis. The employed methodology, strongly supported in ergonomics principles, and in interactional and participatory techniques, contributed to achieve our gold that is what we now call Conceptual Standards. The patterns go beyond of a usual model of book a of ergonomics specification, once incorporating the viewpoint of the end user, it is also a set of best project practices and of project management in conception ergonomics.
\end{abstract}

Keywords: Ergonomics, good project practices, conceptual design patterns, project, workstations

\section{Introduction}

The object of this article is the presentation in the form of material case, of the systematic use of pattern languages in the knowledge managing of ergonomic projects. Based in the Alexander's [1] [2] research, the concept of pattern languages was appropriated to develop recommendations, requirements and concepts that could solve aspects observed in the ergonomic analysis incorporating the informal knowledge in the project as well as the projectual ability. The conceptual design pattern works, in an appropriate form of expression to project tasks, as recommendations developed from the ergonomic analysis and as forwarding improvement opportunities with their own justification. In this greeting they could be, at the same time, assimilated experiences by the pro- ducer team and assailable references by the consulting team.

Hence the essential contribution of this paper is to produce an empirical example of the usability of Ergonomic Design Patterns (EDP), showing its worth for managing experiences of solving general problems in particular contexts.

\section{Backgroud}

The main finality of the Ergonomic is to guarantee the adequation between the agents and the work system [3] [4]. The lack of this perspective meant the existence of a large number of inappropriate situations which require a process of transformation. This transformation happens through projects of situation where the agent will operate, fulfilling the lack of

\footnotetext{
*Corresponding author. E-mail: bernardobastosf@gmail.com
} 
ergonomic requirements in their original conception. Those projects are constituted in two intercomplementary steps, managing changes in a strategic level [5] and the ergonomic action, in the operational and tactical spaces of a given organization [6] [5]. In this last step, the professional ergonomic practitioner, the ergonomist, has the role to conciliate the sociotechnical boundaries of the situations and the physiological and cognitive requirements of their agents. His responsibility is to contribute with the planning, project and evaluation of the task, work stations, products, environments and systems, in order to make them compatible with the needs, abilities and limitations of people [7].

The analytical expertise refers to the methods and techniques used to characterize the situations examined whether they could be referential or objectual. The materials of references profile, beyond the relevant bibliographic elements, a series of specific documentation presumably existing in the demanding organizations.

A projectual capacity gathers the skills and the competences of the team that develops solutions with ergonomic bases.

Within in the scope of this paper, it is not the main problem the methods and tecnics of the analisis that compose the analytic expertise, nor specifically related to the quality of reference materials. The same way, a good projectual capacity it is only a necessarily condition, but not enough for what it could be called as a good ergonomic project.

In face of this dilemmatic structure it is proposed a point of view that a good project would ley down under the combination of consist analytic methods, with the formation of accurate references to the problems on canvas, articulated with the projectual capacity oriented.

The route we chose was the development of pattern language in ergonomics. According to Alexander's proposals [1] pattern languages articulate design elements, such as classes, attributes, operations and relationships between classes. Its fundamental use meets the general dilemma of ergonomic design, common solutions for singular problems. Within Alexander's words we found the following holophrasis: It was important [the pattern approach for design] from the beginning, because one of the characteristics of any good environment is that every part of it is extremely highly adapted to its particularities. The central of his proposition is the basic tenet of Alexander lays over a pregnant idea: no one can better specify his own environment than the own user. Er- gonomic, as user centered design approach, should entirely agree with this lemma.

In our times, design patterns had been widely used in several applications beyond the original architectural field. It is currently adopted by developers for complex systems, especially as when they exhibit characteristics of the increase complexity. It is assume that to achieve a good project; Ergonomic should be considered as an essential part of it, and not as something aside, separated [7]. The project involves the operators' performance and his activity in situation, which brings variability's that should be integrated by the ergonomist. For the ergonomist, these are dimensions that should orient the choices referring the project during the conception process. The conception it is a process of progressive determination of an object or of a work situation and of the action of the work process actors [8]. However, the lack of a managing knowledge device for project management makes that each project do not be constituted as an advance, to the contrary, an eternal beginning. The major interest of design pattern derives from its powerfulness in extracting the common and featured structural information from a system in progressive abstraction level. Ipso facto, as structured as a language - in the acception that it has subjects, objects, attributes, syntax and representation modes we could pertinently suppose that the knowledge management essential problem in ergonomic design could be fairly outlined.

The project concepts are developed, from there on, based on the improvements that were concretized in the ergonomic analysis developed. For Baxter [9], the forging of the concepts it is the stage where occurre the concretization of the requirements and specification of a Project.

Alexander [1] call this process of "consolidation of a pattern". The Ergonomic Design Pattern thus obtained has the following structure, divided into four main parts:

(i) photography of the activity;

(ii) description of the activity;

(iii) recommendations and

(iv) conceptual pattern.

Each conceptual pattern formulated should have a name related to the activity and it is constituted with an image of the concept and the requirements (figure $1)$. 


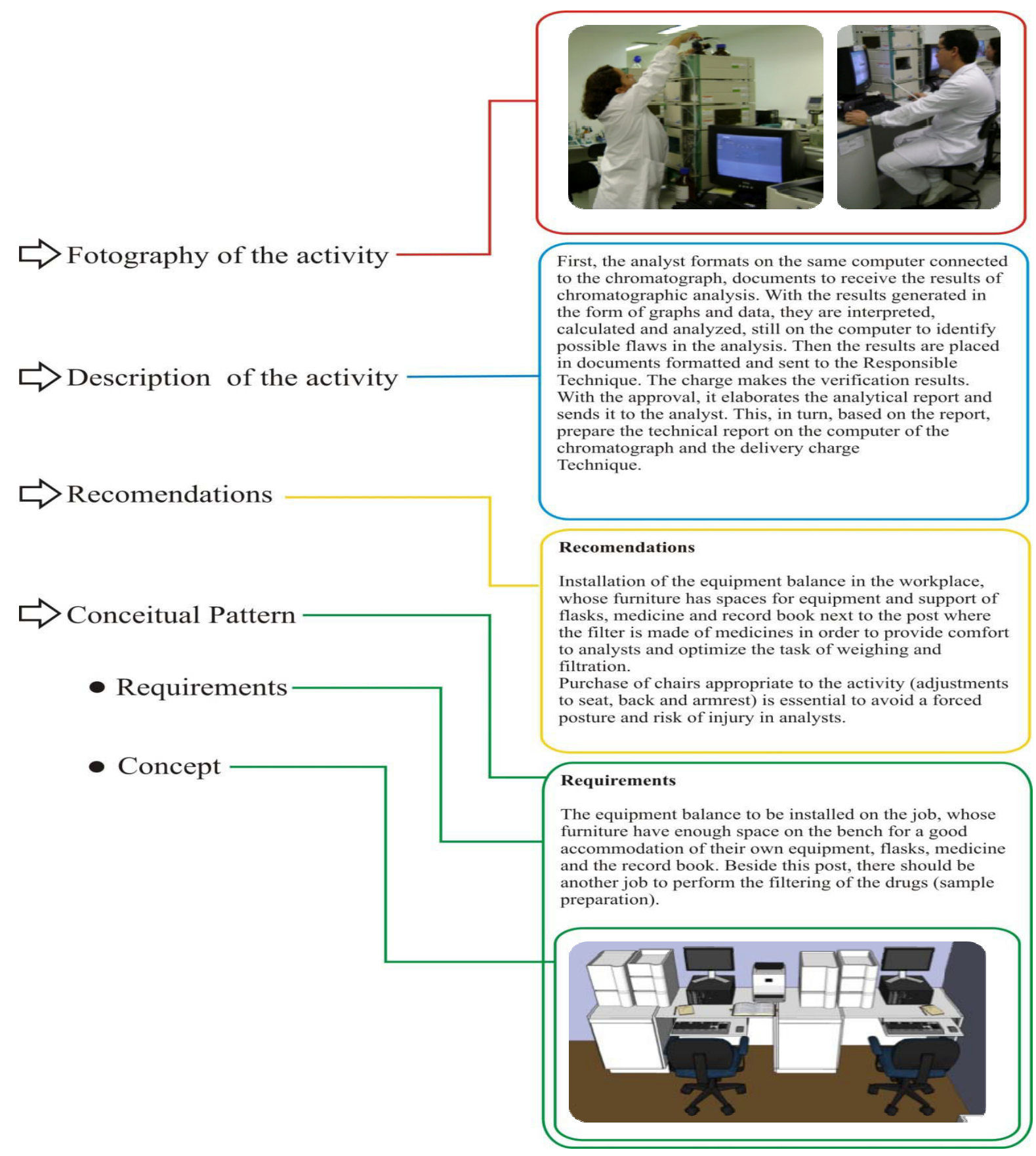

Figure 1: Ergonomic Design Pattern structure 
Some guiding concepts were attempt to functional analysis: The working station (WS) design and the general arrangement (GA) one. Working station design concerns the patterning of the microworld in which operators perform theirs tasks. The GA evaluation looks for the examination of meshing and harmony of the macroworld to which the set of working stations belong [10]. The user centered design of each WS combined into an adequate GA is the targeted to be adopted for an ergonomic design pattern.

\section{Methodological frame}

The formulation of patterns requires a combination of ergonomic analysis, with the organization of documental references and articulating them around the projectual capacity of a given team.

The ergonomic analysis aimed extract (from the functional analysis) and elicit (from the in charge) the criteria related to the implicit project of an examined situations.

The knowledge resulting from the analysis aimed identify the nature of the problems to be addressed. Such ergonomic analysis engender, in each moment, a participatory action of the operators during the explanation of the liquid chromatography task and the work activities observed in loco. The participation was ensured by technical interaction [11], both in observational actions [12] (ergonomic action, selfconfrontation), conversational [13] and participatory ergonomic [14]. The canvas of analysis implies in gathering data about o task performance, equipment used during the activity and the work environment.

The whole process of microanalysis outlined a set of templates. A working template, in EPD signifies not only a physical disposition of elements.

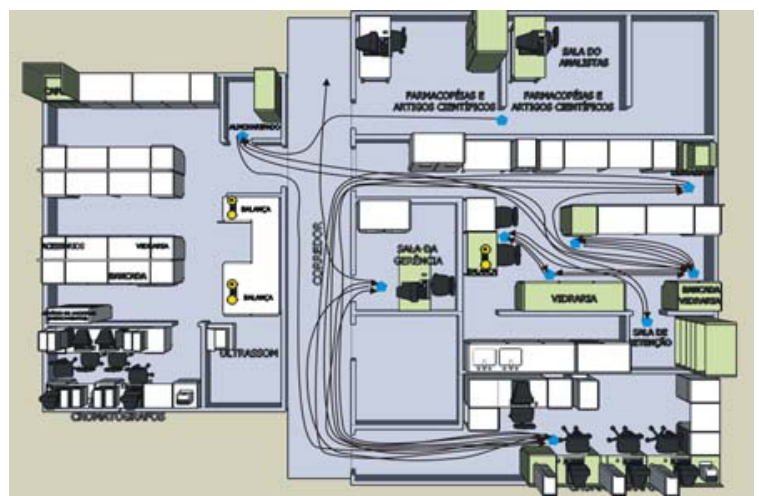

Figure 2. Flowmap of the liquid chromatography activity
It includes a local study about material handling, diverse actions performed, local circulation, stockage, equipments used, relationship between working stations and adequate furniture.

Classes, attributes, operations and relationships between classes were schematized fusing each of these functional units and integrating them in an overall system. Ipso facto it was driven a macro representation of the GA summarizing the study about the form of disposition, the location of this equipments and the workstation into a spatial context.

The design pattern was obtained by building into three steps:

i) outlining a problem dot matrix

ii) outstanding the problem approach

iii) structuring the ergonomic design pattern

The three steps were combined with the free appropriation of the patterns theory developed by Alexander [1] [2] and with the conducting methods of project to develop products [9] [15]. This resulted in the structuring of the ergonomic design pattern.

\section{Results}

In this study, were analized two laboratories that perform the liquid chromatografy process (LCP). The guiding methodology described above made possible the systematic collection of datas, allowing an operative model of the working system of the LCP. This scheme was obtained by means the identification of inherent aspects from the current working.

The general arrangement of the two laboratories that perform the liquid chromatography process is illustrated by the figure 2 .

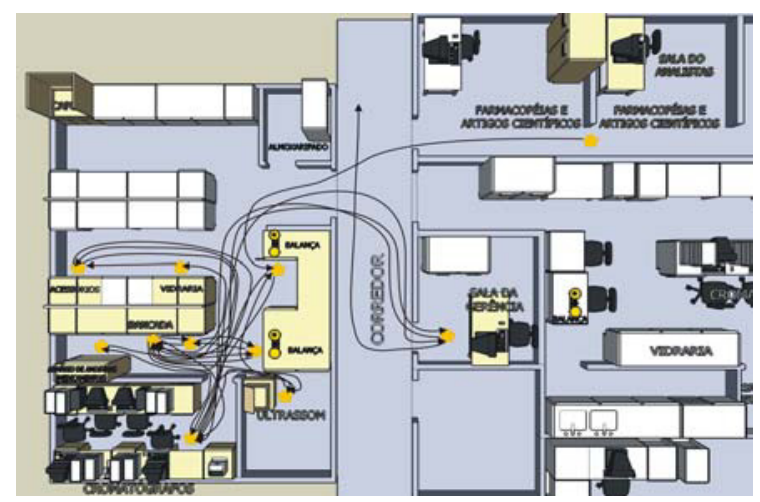


According to Alexander's basic tenet, the elements observed in the activity of two laboratories were extracted from the Ergonomic Analysis and compared with the task (figure 3), in other words, the one that probably the designer has been informed to implement in the project without the user participation.

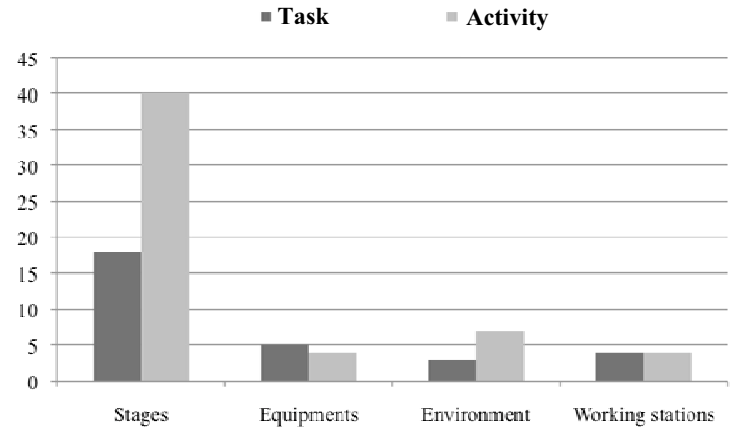

Figure 3. Number of aspects related to the activity and task of the two LC laboratories

\section{Analysis}

The figure 3 shows the dissonance that there is between task and activity. The distance between task and activity can be interpreted how the user's lack on the project of the working station and environment working, or a lack of planning considering the variables present in the performance of work.

In the ergonomics analysis the ergonomists identified project issues in the environment working that affect in the process of chromatography. This identification occurred with operators' collaboration and with the ergonomists' expertise.

In the analyzed laboratories appeared several nonconformities related to layout, configuration and working station project. Consequently, several issues of the activities performed there did not be considered. This fact induced constraints to operators and an unsatisfying operation of the laboratory activities. For future laboratories do not exhibit the same nonconformities, it necessary to develop project concepts with suggestions and specifications of the project good practices to recurrent context.

\section{Ergonomic Design Pattern of the LCP}

The comprehension of the working context and the list of issues identified in the analysis resulted in a table (table 1). The table aims to structure and to group the issues according to the activity and to the environment where the activity is performed.

Table 1. Organization of the identified problems from the analyzed activities

\begin{tabular}{c|l}
\hline \multirow{3}{*}{ Subject-matter 1 } & Issue 1.1 \\
& Issue 1.2 \\
& Issue 1.3 \\
& Issue $1 . \mathrm{n}$ \\
\hline \multirow{3}{*}{ Subject-matter 2 } & Issue 2.1 \\
& Issue 2.2 \\
& Issue 2.3 \\
& Issue 2.n \\
\hline \multirow{3}{*}{ Subject-matter 3 } & Issue 3.1 \\
& Issue 3.2 \\
& Issue 3.3 \\
& Issue 3.n \\
\hline \multirow{2}{*}{ Environment } & Environment Issue 1 \\
& Environment Issue 2 \\
& Environment Issue $\mathrm{n}$ \\
\hline
\end{tabular}

The table 1 allowed to contextualize each issue into its context. This way it was possible to develop each identified issue in the ergonomics analysis. The table 1 displays the issues' impacts in the operator and the repercussions on the organization, the improvement recommendation to the issue identified, and the justification for the adoption of the improvement recommendation (table $\mathrm{X}$ ). The improvement recommendation were developed and validated with the operators of the laboratories. This fact provided largest involvement of the operators when they proposed possible solutions to the projectual issues. The operators' participation is essential in the analysis process and in the development of the projectual solutions [16] [17] [18]. 
Table 2. Development of issue solving

\begin{tabular}{ll}
\hline Problem 1.1 & Description of the issue \\
\hline Impact & $\begin{array}{l}\text { Description of negative im- } \\
\text { pacts in operator's health } \\
\text { and the repercussion in the } \\
\text { organization. }\end{array}$ \\
$\begin{array}{l}\text { Improvement } \\
\text { Recommenda- }\end{array}$ & $\begin{array}{l}\text { Project recommendations } \\
\text { developed with the opera- } \\
\text { tors participation and vali- } \\
\text { dated by them. }\end{array}$ \\
Justification & $\begin{array}{l}\text { Justify the project recom- } \\
\text { mendations for them to be } \\
\text { implemented. }\end{array}$
\end{tabular}

The development of the issues provides the beginning of the process of formulation of the Ergonomics Design Pattern combined with the methods of conducting project for product development. The identification of the laboratory issues is considered as a specification of futures projects, base in the Ergonomic concepts: safety, welfare, efficiency, productivity and health. The improvement recommendations for the outlined issues are considered as preliminary specifications of the project, in other words, what the product should have. Besides, the justifications related to each improvement recommendation of the laboratories issues corroborate with the project requirements to be incorporated into products that will be developed.

This set, permeated by the perception and feelings of the user, provides grants to finalize the Conceptual Design Standards, with the formulation of concepts that will compose each of the patterns developed. The definition of the concept occurs after the validation process with the operators [19].

A conceptual pattern is more than a product specification, once the technical data are only one of the components pattern. The concepts of the pattern have the role to serve as requirements for artifact projects, environments or working systems. They are recommendation for futures projects with similar context. It is where the specification is improved. These projectual recommendations, in this specific case, aim to attend the chromatography process, not just those laboratories analyzed.

By building a conceptual pattern for a Subjectmatter, the remaining patterns developed have a project relationship with the others subject-matters and with the environment. They have interdependence, because one pattern it is not enough to solve all of the inadequacies of the Project. The conceptual pattern "environment", it meshes all of the patterns. This occurs because all of the patterns of each subject-matter are integrated into a same work environment.

\section{Discussion}

The Ergonomics Designs Patterns illustrate clearly and objective the functioning and suggestions of the good practices of projects. They demonstrate full adaptation to the activities of liquid chromatography and to the laboratories analyzed. By implementing of patterns, problems and constraints identified tend to be suppressed. This results in quality, safety, efficiency and comfort in the process of chromatography, in the working context and in the workplace, especially the safety of who act in laboratories, day-today. The developments of Ergonomics Designs Patterns provide to designers vital informations coming from the informal knowledge. These informations are often limited to these professionals. The development of EDP can optimize the process of projectual action, what decrease time of development of projects. Therefore it provides a fair appropriation of these informations to the activities performed in the workplace.

Participation of operators throughout the development of EDP made possible the success of this work. Good cooperation with stakeholders in the study resulted in suitable project solutions of workperformance to the activities of liquid chromatography. This integration based on the principle that no one better than the operator to design their own working environment, an essential factor for the development of EDP.

In the Ergonomic Design Pattern, improvements will be designed to have better projects and concepts, according to work activity and the needs of workers. This occurs from the concepts developed. The requirements set out in EDP provide to the designer and his team a project development more effectiveness with the qualities of safety and efficiency. In other words, the results obtained have the main function provides the projects information, which enable a good development project of efficient working environments, safe, comfortable and suitable for future activities and to operators who will work there. 
The study developed in the laboratories stand out by having important function in the development of the Ergonomic Design Pattern. As an emerging theme in the area of ergonomics, it contributes for future studies to better understand the practice of developing requirements for working context. The EDP provides projectual information that to enhance the wellbeing, comfort, safety, health, efficiency and employee productivity. Hence it is important for Ergonomics. Also important to emphasize that the appropriation of principles of the theory of patterns lack a unique methodology. It opens the way for us to identify a method directed to the ergonomic analysis of project, perhaps we should say for Ergonomics of Conception.

\section{References}

[1] Alexander C, Ishikawa S, Silverstein M, 1977. A Pattern Language: Towns, Buidings, Construction, Oxford University Press, New York

[2] Alexander C, 1979. The Timeless Way of Building, Oxford University Press, New York.

[3] Wisner A., 1993. A metodologia na Ergonomia : ontem e hoje. In: Wisner A. Textos selecionados de ergonomia. Fundacentro, São Paulo.

[4] Hendrick, H., 1991. Adaptation, development and palication of tools and methods for macroergonomic field research. Queinnec Y. \& Daniellou F. - Designing for everyone. Proceedings of the Xith Trinnial Congress of The International Ergonomics Association, Taylor and Francs, London, 1181 1183

[5] Zink et al, 2008. Comprehensive change management concepts Development of a participatory approach, Applied Ergonomics, 39, 527-538.

[6] Vidal, M. C., 1995. Sobre o trabalho de pesquisa em equipe integrada de pesquisa: construindo uma orientac ão em rede. I Congresso Internacional de Engenharia de Produc ão, São Carlos, 1995

[7] Corlett, E. N., Clark, T. S., 1995. The Ergonomics of Workspaces and Machines: A design manual. Florida: 2a edic ão - CRC PRESS

[8] Béguin P, 2004. "L'ergonome, acteur de la conception", In: Falzon P, Ergonomie, Presses Universitaires France, Paris.

[9] Baxter M, 2002. Product design: A pratical guide to system-atic methods of new product development, Nelson Thornes Ltd, Cheltenham.

[10] Fiedler, N. C. et al., 2009. "Otimizac ão do layout de marcenarias no sul do Espírito Santo baseado em para metros ergono micos e de produtividade", Árvore, vol. 33, n. 1, pp. 161-170

[11] Bonfatti R, Vidal M, 2003. Conversational Action: an Ergonomic Approach to Interaction. In: Collin Grant. (Org.). Rethinking communicative interaction, J B Publishing Co., Am-sterdam.

[12] Vidal, M. C. R., Muniz, H. P., Alvarez, D., 2001. Terá a atividade um lugar na avaliação de performance do setor de serviços?. Ação Ergonômica, vol. 1, nº 2, pag. 79.

[13] Vidal, M. C., 2008. Guia para Análise Ergono mica do Trabalho (AET) na empresa: uma metodologia realista, ordenada e sistematizada. Rio de Janeiro: 2a edic ão Virtual Científica.

[14] Wilson J.R, Haines H.N, 1997. Participatory ergonomics. In: Salvendy, G. (Ed.), Handbook of Human Factors and Ergonomics, Wiley, Chichester, 490-513.

[15] Palh G, Beitz W, Feldhusen J, Grote K, 2007. Engineering Design: A systematic Approach, Springer, London, United Kingdom.

[16] Khai T.T, Kawakami T, Kogi K., 2005. Participatory Action Oriented Training: PAOT Programme Trainer's Manual. Centre for Occupational Health and Environment, Cantho.

[17] Kogi K, 2006. Participatory methods effective for ergonomic workplace improvement, Applied Ergonomics, 37, 4, 547554.

[18] Pilemalm S, Lindell P, Hallberg N, Eriksson H, 2007. Integrating the Rational Unified Process and participatory design for development of socio-technical systems: a user participa-tive approach, Design Studies, 28, 3.

[19] Broberg O, Andersen V, Seim R, 2011, Participatory ergonomics in design processes: The role of boundary objects, Applied Ergonomics, 42, 464 - 472. 